\title{
Focus on Challenges and Development of Sports Physiology
}

\author{
Zimin Chang, Liang Li
}

Nanchang Institute of Science \&Technology, Nanchang 330108,China

Keywords: sports physiology; course; challenges

\begin{abstract}
Sports physiology is one of the basic theories of sports, which is based on the guidance of scientific and reasonable movement. Due to the limitation of our national conditions, the development of sports physiology is very tortuous, and its development is very slow. At the present stage of our country, the sports physiology is facing the challenges that emerge in endlessly. In this paper, a brief analysis and exploration on the current situation and challenges of China's sports physiology, and further puts forward the measures and solutions to the problems, provides theoretical support for the future development of China's sports physiology.

Sports physiology can be included within the category of human physiology, sports physiology in normal human body as the research object, mainly studies the human body in response to sports and the ability to adapt to changes, it is a study of the human body when in the activities of the various aspects of the subject. On this basis, this paper provides a theoretical reference for the development of physical education, sports training and fitness training.

Main tasks of sports physiology: research on the physiological principles in the course of physical education; based on the correct understanding of the function of the human body activity patterns, in-depth exploration of the development of sports on human body function; understand the different training level, different sports and athletes of different gender, different age and the different physiological characteristics, in order to guide sports training, scientific and effective organization of sports teaching, and more effective service in sports practice.

Sports physiology provides an effective reference for sports and physical training, sports physiology plays a vital role in the promotion of sports and sports performance. So many countries have stipulated the sports physiology is a compulsory course for physical education teachers and full-time coaches, and strict requirements of sports teachers and coaches must pass on the knowledge of sports physiology into daily teaching practice. It is of great importance to apply the principles of physical exercise to the teaching of physical education in order to explore the effects of improving sports or training.
\end{abstract}

\section{Introduction}

In the late nineteenth Century, sports physiology research appeared in Germany and the United States. Zanci and Bennett as outstanding scientists. The first proposed muscle fatigue, and carry out a comprehensive and systematic in-depth research, finally draws the curve of muscle fatigue. At the same time, the British scientist Hill also launched related to participation in body movement in response to intense research, by 1930s, Skald Roman, outstanding scientists fisk established the system theory of body function. In 1950s, scientists such as He Xuli and Hansen put forward the famous theory. In 60s, Bogerst Ron conducted a needle biopsy of skeletal muscle, which laid a solid foundation for the development of sports physiology. Oster Lang and Rodale in 1970 published the book "sports physiology", so far, sports physiology is the theoretical basis of the system, this book comprehensively and fully reflect the achievements of the late nineteenth century to the twentieth 
century modern sports physiology.

\section{Challenges in the research and education of sports physiology.}

Challenges for scientific research. Competition for efficiency of research funding. In recent years, changing from the domestic and international political and economic environment, a variety of sports physiology and resources and survival period were significantly reduced in different degree, but the research in the field of growing and research projects are also increasing, which caused the fierce competition on scientific research funds. With the increasing complexity of scientific research, the cost of scientific research is also increasing. Based on this fact, the research of experimental science, especially the basic scientific research, should be kept in an unprecedented challenge.

The model cooperation between researchers need to improve. The traditional research mode is a human subject single, experimental study of communication is to research the individual and group communication, low scientific research projects on cooperation even if there is cooperation, it does not belong to the scientific research cooperation in the full sense, mostly only stay in on a given issue at the technical level. Therefore, at this stage of research and cooperation model needs to be improved, single person playing the world era has passed, the new era of scientific research is the need for teamwork. The quality of scientific research personnel is challenged.

With the continuous change of the external environment of scientific research, the researchers of sports physiology are challenged by the knowledge and ability. The speed of scientific research development in the new period of accelerating the speed of knowledge updating is accelerating, so to adapt to the fast-paced era, scientific research personnel's quality is difficult to keep up with the pace of updating of knowledge, scientific research become the most realistic challenge.

\section{Challenges for Education}

Teaching system needs to be improved. The research shows that the sports physiology experiment in many sports colleges and universities is in the course of the theory of science and technology. As a result, the experimental course of sports physiology is often limited by the total term of the semester, the class is seriously insufficient, and what's more, the experimental class is run by the theory class and the experimental items are replaced or changed randomly. Teaching and obvious problems also exist in the form in the experimental class, the new reform model is an experiment in several classes were usually taught, thus greatly increased the sports physiology workload of teachers, to encourage the distribution of this issue has not been embodied. The sports physiology teacher reluctant to increase class and experimental class content, reluctant to reform the original teaching mode, improve the university education system seriously restrict the sports physiology teaching enthusiasm.

The external environment restricts the development of teaching and scientific research. Education is the development of sports physiology hope, sports physiology in the future, so only the timely research results of sports physiology applied to college sports teaching and sports training, can truly reflect the value of the research significance and the research of sports physiology. For the realistic restriction, despise teaching research of current society sports psychology phenomenon, many sports physiology students when choosing a career, usually based on reality and the choice of sports injury in sports teachers or doctors and other professional fields of employment, related physiological science research not popular. The reason is that under the background of social industrialization, the employment market of sports physiology has been decreasing, and the employment opportunities are decreasing correspondingly. The sports colleges and universities in 
our country though the sports physiology course construction professional in continuous improvement, but to a higher level of scientific research and practical textbooks lack of textbooks, update speed is very slow, the physiological system of long-term professional knowledge behind the developed countries, students gain a deeper knowledge of difficulties. In this case, to cultivate successors of sports physiology outstanding, the need for a substantial increase in the cost of education, it will increase the burden of all aspects of sports physiology, and will bring new challenges to the future long-term development of sports physiology.

Serious lag in teaching content. Under the new situation, due to the experimental course belongs to the scope of management of the teaching and research section, the experiment is relatively independent flat and low, and may appear different courses because of the same experimental content and experimental repetition phenomenon.

The current situation of college sports physiology is that most of the sports physiology teaching mode tends to be rigid, experimental methods are still outdated, the teaching content of sports physiology is updated slow, the contents of the old books at present, a lot of sports colleges and universities selected teaching content or higher education press published the traditional materials, or other materials kinematics overall, the teaching content not only very slowly especially and rigid teaching. Aspects of the study, and the era of serious dislocation, the production front and social services are not serious tune. In the classroom, teachers still occupy a dominant position, the protagonist of the classroom, teaching methods are old and many years did not change, cannot achieve the goal of teaching, eventually led to a serious lack of students' ability of innovation and application.

Serious lag in teaching content. Under the new situation, the experimental course belongs to the Department of management, so the experiment is relatively independent, which leads to the low level of design and experiment content, and may lead to different courses for the experimental content caused by the same experiment was repeated phenomenon.

The current situation of college sports physiology is that most of the sports physiology teaching mode tends to be rigid, experimental methods are still outdated, the teaching content of sports physiology is updated slow, the contents of the old books at present, a lot of sports colleges and universities teaching content selection, either the higher education press published the traditional materials, or other materials kinematics overall, the teaching content not only very slowly especially and rigid teaching aspects of the study, and the era of serious dislocation, the production front and social services are not serious tune. In the classroom, teachers still occupy a dominant position, the protagonist of the classroom, teaching methods are old and many years did not change, cannot achieve the goal of teaching, eventually led to a serious lack of students' ability of innovation and application.

In the sports teaching, appropriate arrangements for sports games can active classroom atmosphere, enrich the teaching content, to stimulate interest in learning, improve teaching quality, promote students' physical, psychological and social adaptation ability of all-round development. So in the sports teaching, must be based on the correct understanding of the essential characteristics of sports games on the rational use of sports games, sports games with good treatment and precautions, with purpose, plan selection, organization of sports games, and constantly improve the quality and effect of the use of sports games, make it an effective means and important content of sports teaching.

Not pay attention to experimental courses. The fact that the theory is more important than the practice exists in China's higher education for a long time, not to preview before class, and not familiar with the operation process of the case, the blind expansion experiment, resulting in some 
experimental results when errors occur, may lead to more serious experimental operational errors, and thus a threat to the personal safety of students what is more, some of the teachers, has the negative attitude of the experimental class, holding the experiment tasks to the professor, the development of students seriously irresponsible.

The main reasons are as follows: in the traditional education concept, physical training has been the focus of the teaching of physical education. The overall teaching environment in colleges and universities has its limitations, which is mainly manifested in the existence of practical utilitarianism.

\section{The future development of sports physiology}

Strengthen scientific research cooperation. Since the birth of the discipline of sports physiology, it has been in the intersection of various disciplines. This domain, need to study different subjects, strengthen the unity and cooperation of different teams, different from individual differences in training, interest, and truly seek common ground, only in this way can we break the traditional mode of cooperation, expanding the research field of vision, improve the efficiency of research.

Strengthen discipline cooperation. The development of sports physiology is promising, but in order to be successful in financing, sports physiology must strengthen cooperation with other disciplines. With other interdisciplinary collaboration can ensure the accuracy of sports physiology research, improving the efficiency of sports physiology, provide more opportunities under the new situation for the development, quality of life and health of human diseases every hour and moment are facing challenges, such as cancer, obesity and Alzheimer's disease and other health problems, which need to be studied collaboration of different disciplines, and that physical activity is the impact of these health problems, the most important factor, so the sports physiology association to become the strongest one, and occupy an important position in many research disciplines.

Actively cultivate new research talents. Talent is hope, talent is the future, especially young people's participation, so we need to pay more attention to recruit new problems, expanding research team. of course, the quality of talent is the key. In order to enhance the ability of the new challenge, we must strengthen the understanding of the professional level, in particular, to strengthen the awareness of the new challenges, so that new people always ready to meet the challenges. The development of science and technology can not be separated from the support of talents, especially the cultivation of reserve talents, which is an important guarantee for the future development of sports physiology.

Increase investment in education. In order to speed up the development of sports physiology, only by increasing the investment in education can we ensure the sustained and stable development of sports physiology. Research results will be delivered to the thinking process of students through education, can greatly shorten the time for students to obtain knowledge, and improve the training efficiency, finally can promote the speed of development of sports physiology education, can effectively guarantee the physiological sustainable development, to provide more high-quality talents for sports physiology research.

\section{Conclusion}

From the time of birth, sports physiology is a young discipline, but for its research at home and abroad has made great progress. The emphasis of the research of sports physiology is on the molecular mechanism and the effect of exercise on human pathology. For example, the study of athletes' health, sports and rehabilitation, sports ability. Based on this research, the practitioners of 
sports physiology must start from the national health and provide effective scientific methods and methods for the national sports and training. At the same time, sports physiology should better serve humanity, it needs to continue to develop and improve. in the development process. sports physiology will inevitably encounter various problems and challenges, which requires us take a positive attitude.

\section{References}

[1]Li T. On the Present Situation and Reform of Experiment Teaching of P.E. Major's Sports Physiology at Jishou University[J]. Wushu Science, 2015.

[2]Ivanov P C, Liu K K L, Bartsch R P. Focus on the emerging new fields of network physiology and network medicine[J]. 2016, 18(10):100201.

[3]Pyne D. Challenges and opportunities in sports physiology[J]. International Journal of Sports Physiology \& Performance, 2008, 3(1):1.

[4]Tian Y, Xiao W, Yao L, et al. Opportunities, Challenges and Countermeasures in the Development of China's Sports Social Organization in the New Period[J]. Journal of Hebei Institute of Physical Education, 2015.

[5]Hua Z S, Yang Y. Opportunities and Challenges: Development and Insight of Sports News Research Overseas[J]. Journal of Chengdu Sport University, 2014. 